\title{
Study of Various Gastrointestinal Tract Lesions by Endoscopic Biopsies in a Tertiary Care Centre of Rural District of Maharashtra
}

\author{
Preeti Rajendra Sahu ${ }^{1}$, Kishor Madhukar Hiwale², Sunita Jayant Vagha ${ }^{3}$ \\ 1,2,3 Department of Pathology, Jawaharlal Nehru Medical College, Acharya Vinoba \\ Bhave Rural Hospital, Sawangi (Meghe) Wardha, Maharashtra, India.
}

\section{ABSTRACT}

\section{BACKGROUND}

In a developing country like India, vast difference exists in people's religion, culture, and socio-economic condition and along with it, there exists a significant difference in their dietary habits. This has led to an incidence of a large spectrum of gastrointestinal (GI) diseases which is different in different geographical locations. The study was undertaken for studying the spectrum of various histopathological lesions of gastrointestinal tract with the help of endoscopic biopsy.

\section{METHODS}

This cross-sectional study was carried out in a span of 2 years in the histopathology division. The study included 105 patients who had GI complains and underwent endoscopic biopsies for the same.

\section{RESULTS}

The present study included a total of 105 cases out of which there were 64 cases ( 61 $\%$ ) of upper GI tract biopsies and remaining 41 cases (39\%) were of lower GI tract biopsies. Among 64 (100\%) cases of upper GI biopsies, reflux oesophagitis (4.67\%) was the most common in non-neoplastic lesions while well differentiated squamous cell carcinoma $(20.31 \%)$ was the most common neoplastic pathology. In gastric biopsies, chronic atrophic gastritis (3.12\%) was the most common condition in a non-neoplastic category, while gastric adenocarcinoma (15.61\%) was the malignant lesion which was found. Among duodenal biopsies, the most common lesion was eosinophilic enteritis / duodenitis (14.06 \%). Among 41 (100\%) colonoscopic biopsies, the most common lesion was chronic non-specific inflammation (12.19\%) under non-neoplastic category, while well differentiated adenocarcinoma (46.34\%) was most common entity under malignant category in our study. Non-neoplastic lesions were more common in upper GI endoscopic biopsies whereas, neoplastic lesions were more frequently seen with lower GI endoscopic biopsies.

\section{CONCLUSIONS}

Performing endoscopy alone is an incomplete investigative modality for the diagnosis. While performing endoscopy and simultaneously taking biopsy for histopathological evaluation helps in giving an accurate diagnosis.

\author{
Corresponding Author: \\ Dr. Preeti Sahu, \\ Department of Pathology, \\ Jawaharlal Nehru Medical College, \\ Acharya Vinoba Bhave Rural Hospital, \\ Sawangi (Meghe) Wardha, \\ Maharashtra, India. \\ E-mail: preetisahu9811@gmail.com
}

DOI: 10.14260/jemds/2021/242

How to Cite This Article:

Sahu PR, Hiwale KM, Vagha SJ. Study of various gastrointestinal tract lesions by endoscopic biopsies in a tertiary care of center of rural district of, Maharashtra. J Evolution Med Dent Sci 2021;10(16):11351139, DOI: 10.14260/jemds/2021/242

Submission 25-12-2020,

Peer Review 19-02-2021,

Acceptance 26-02-2021,

Published 19-04-2021.

Copyright (C) 2021 Preeti Rajendra Sahu et al. This is an open access article distributed under Creative Commons Attribution License [Attribution 4.0 International (CC BY 4.0)]

\section{KEY WORDS}

GIT, Endoscopy, Endoscopic Biopsy 


\section{BACKGROUND}

Gastrointestinal disorders are one of the most common clinically encountered problems which a physician comes across in a day-to-day practice with a high degree of morbidity and mortality. ${ }^{1}$

Gastrointestinal tract (GIT) is a site for a variety of lesions including inflammatory disorders, infectious, mechanical conditions, toxic and physical injuries, vascular disorders and neoplasms. ${ }^{2}$

This spectrum of pathological lesions varies greatly due to above mentioned epidemiological and cultural factors. It often requires histopathological diagnosis for their conclusive diagnosis. In the era of evidence-based medicine, there is utmost importance given to the diagnosis of the disease before any intervention is planned for it. Now a days the treatment plan has become very specific not only to the diagnosis but also the stage, grade and related possible complications even before the start of the therapy. Hence, diagnostic modalities and techniques have evolved many folds in this era of modern medicine.

In the olden days the imaging modalities used to give a clue to the diagnosis, but it failed to give a confirmatory diagnosis in terms of histopathological confirmations. Flexible endoscopes have given access to the tissues of those regions which were earlier not possible to be visualised preoperatively. As the diagnosis are not always straight forward on routine endoscopy, histopathological examination of biopsies obtained by endoscopes remain the cornerstone in giving the diagnosis to the patient. Therefore, this preoperative tissue diagnosis has given the ability to treat each and every patient with a specialised and standardized treatment based on their current disease status, stage or grade. Histopathological diagnosis of endoscopic biopsies is a critical determinant of future cancer risk and screening interval. The pre-operative tissue diagnosis is done broadly by two techniques, fine needle aspiration cytology (FNAC) and Biopsy. While FNAC is an easier, less invasive, cost effective method for tissue diagnosis however, it is not a confirmatory technique. Hence, for areas which are inaccessible and can only be accessed through endoscopy, biopsies are preferred over FNAC.

Upper GI endoscopy of oesophagus, stomach and duodenum permits the direct visualisation of the mucosal surface and thus provides us much more information than that gained by 2-dimensional scans and $\mathrm{x}$-rays of the respective areas providing the platform for retrieval of tissues from the abnormal areas for histopathological diagnosis of benign as well as malignant lesions, because the gross findings on endoscopy are not always disease specific and these findings may overlap with various other gastrointestinal pathologies. Colonoscopy along with biopsy includes direct visualisation of entire mucosa of colon, rectum or anal canal and performing biopsies from the representative pathological lesion. Endoscopy is a valuable tool in the diagnostic workup of GI complaints. ${ }^{3}$ Histopathological examination not only aids in narrowing down the differential diagnosis to a definitive diagnosis, but also helps in determining the course of disease, therapeutic responses and early identification of any untoward complications of several pathologic lesions by serial endoscopic biopsies. The study was undertaken for observing the spectrum of various histopathological lesions of gastrointestinal tract with the help of endoscopic biopsy.

\section{METHODS}

This was a cross sectional study carried out in a span of 2 years from October 2018 to October 2020 in the histopathology section of Department of Pathology. The study was conducted among 105 patients who had GI complains and underwent endoscopic biopsies for the same.

\section{Sample Size Estimation}

Sample Size

$$
N=\frac{\mathrm{Z} \alpha}{22 \cdot \mathrm{P} \cdot(1-\mathrm{P})}
$$

Where $\mathrm{N}=$ required sample size"

" $\mathrm{Z} \alpha / 2$ is the level of significance at $5 \%$ that is $95 \%$ "

"Confidence interval $=1.96$ "

$\mathrm{P}=$ Prevalence of diagnostic diseases in higher-middle ETL = $1.7 \%=0.017$

$\mathrm{d}=$ Desired error of margin $=2.5 \%=0.025$

$\mathrm{n}=1.96^{2} \times 0.017 \times(1-0.017)$

$0.025^{2}$

$=102.71$

$=105$ patients were required in the study.

\section{Inclusion Criteria}

- Endoscopic and colonoscopic biopsies from oesophagus, stomach, duodenum, colon, rectum and anal canal.

- Male and female both of all age group.

\section{Exclusion Criteria}

- Patients who had already received treatment for gastrointestinal malignancy.

- Biopsies from oral cavity and pharynx.

- Recurrent cases of upper gastrointestinal tract and lower gastrointestinal tract carcinoma.

- Esophagectomy specimens, colectomy specimens, resected specimens of colon and stomach.

The biopsy was taken after endoscopic examination. After adequate fixation of biopsy sample, routine processing was done followed by embedding in paraffin keeping mucosal surfaces up. Five-micron thick sections were cut perpendicular to the surface. Each section was stained and studied microscopically with haematoxylin and eosin (H \& E) They were segregated into different histopathological patterns after pathological findings were noted and diagnosis was made.

\section{Statistical Analysis}

The data collected was tabulated in a master chart, calculations were done and analysed accordingly. The quantitative and qualitative variables were expressed in terms of percentages. 


\section{RESULTS}

Present study included a total of 105 cases out of which there were 64 cases ( $61 \%$ ) of upper GI tract biopsies and remaining 41 cases (39\%) were of lower GI tract biopsies.

In upper GI cases, out of 64 cases there were 39 males and 25 females while in lower GI cases, out of 41 cases there were 26 males and 15 females. Total study included 65 males and 40 females constituting 105 cases.

The study included 64 (100\%) biopsies of upper GI tract out of which 24 patients had (37.5\%) oesophageal biopsy, 21 $(32.82 \%)$ patients had biopsy from duodenum, and 19 (29.68 $\%$ ) patients had biopsy from stomach. Lower GI tract lesion biopsies constituted of $41(100 \%)$ cases, out of which 18 patients (43.9\%) had rectum biopsies, 17 (41.5\%) patients had biopsy from colon, 3 (7.3\%) patients had biopsy from anal canal, 2 (4.9\%) had ileocaecal and 1 (2.4\%) patient had rectosigmoid biopsy.

Present study consists of $64(100 \%)$ cases of upper GIT biopsies, out of which there were 34 (53.13 \%) non-neoplastic cases comprising of 33 inflammatory cases and 1 (1.57\%) non-specific case. Out of 33 inflammatory cases, 6 cases each were of oesophagus and stomach \& 21 cases were of duodenum. Out of 6 cases of oesophagus there were $3(4.67 \%)$ cases of reflux oesophagitis and $1(1.57 \%)$ case each of Barrett's oesophagus, candidal oesophagitis and healed oesophageal ulcer. Out of 6 cases of gastric biopsy there were $2(3.12 \%)$ cases of chronic atrophic gastritis and 1 case $(1.57$ $\%)$ each of eosinophilic gastritis, granulation of chronic inflammation-peptic ulcer origin, acute on chronic gastritis and chronic non-specific gastritis. Out of 21 cases of duodenum there were $9(14.06 \%)$ cases of eosinophilic enteritis / duodenitis, 4 (6.25\%) cases of chronic non-specific inflammatory inflammation; 3 (4.67\%) cases of non-specific duodenitis; 2 (3.12\%) cases each of celiac disease and tropical sprue \& $1(1.57 \%)$ case of granulation of ulcer. There was 1 $(1.57 \%)$ case of pseudoepitheliomatous hyperplasia under non-specific category of oesophagus. Remaining 3 (4.69\%) were of normal morphology consisting of 2 (3.12\%) cases of oesophagus and $1(1.57 \%$ ) case of stomach. (Table 1 )

There were 27 neoplastic cases out of 64 cases of upper GI. Out of 27 cases there were $2(3.12 \%$ ) cases of benign epithelial polyp of stomach and 25 cases of malignant lesions comprising of 15 oesophageal and 10 gastric biopsies. Out of 15 cases of oesophagus there were $5(7.81 \%)$ cases of well differentiated and $4(6.25 \%)$ cases each of moderately differentiated and poorly differentiated squamous cell carcinoma \& 2 (3.12\%) cases of well differentiated adenocarcinoma. Out of 10 cases of gastric biopsy there were 5 (7.81\%) cases of well differentiated adenocarcinoma, 3 cases ( $4.68 \%$ ) of signet ring adenocarcinoma and 2 (3.12\%) cases of moderately differentiated adenocarcinoma. (Table 2).

Present study comprises of $41(100 \%)$ cases of lower GI out of which 16 (39.02\%) were under non-neoplastic category. Out of 16 cases there were 15 inflammatory lesions and $1(2.44 \%)$ case of vascular ectasia under non-specific lesion of rectum. Out of 15 cases of inflammatory lesions there were 2 (4.88\%) cases of ileocecal junction which had 1 (2.44 $\%)$ case each of eosinophilic enteritis and tuberculosis; 7 cases of colon consisting $4(9.75 \%)$ cases of chronic non-specific colitis, 2 (4.88\%) cases of eosinophilic colitis, and 1 (2.44\%) case of ulcerative colitis; 1 (2.44\%) case of retrosigmoidal biopsy which had ulcerative colitis and 5 cases of rectal biopsy consisting 1 (2.44\%) case each of ulcerative colitis, Crohn's disease, eosinophilic proctitis, chronic non-specific proctitis and granulation of ulcer. Remaining 3 (7.32\%) were of normal morphology consisting of $1(2.44 \%)$ cases of colon and 2 (4.88 $\%)$ cases of rectum. (Table 3 )

There were 22 (53.66\%) neoplastic cases out of 41 (100 $\%$ ) lower GI cases of which 3 cases were benign and 19 cases were malignant. Out of 3 benign lesions there were 2 cases of colon, $1(2.44 \%)$ each of epithelial polyp and adenomatous polyp \& 1 (2.44 \%) case of squamous papilloma of anal canal. Out of 19 cases there were 7 cases of colon, 10 cases of rectum and 2 cases of anal canal. Out of 7 cases of colon there were 6 $(14.63 \%)$ cases of well differentiated adenocarcinoma and 1 $(2.44 \%)$ case of papillary adenocarcinoma. Out of 10 cases of rectum, there were $4(9.75 \%)$ cases of well differentiated adenocarcinoma, 2 cases (4.88\%) each of moderately differentiated adenocarcinoma, papillary adenocarcinoma and signet ring adenocarcinoma. There were 2 malignant cases in anal canal, 1 (2.44\%) case each of well differentiated and moderately differentiated adenocarcinoma. (Table 4).

\begin{tabular}{|c|c|c|c|c|}
\hline & $\begin{array}{c}\text { Sub- } \\
\text { Division }\end{array}$ & $\begin{array}{c}\text { Site Wise } \\
\text { Distribution }\end{array}$ & $\begin{array}{l}\text { Histopathological } \\
\text { Diagnosis }\end{array}$ & Percentage \\
\hline \multirow{16}{*}{$\begin{array}{c}\text { Non- } \\
\text { neoplastic } \\
34 \text { out of } \\
64 \\
(53.13 \%)\end{array}$} & \multirow{15}{*}{$\begin{array}{l}\text { Inflammatory } \\
\text { lesions of } \\
\text { upper GIT } \\
(\mathrm{N}=33)\end{array}$} & \multirow{4}{*}{ Oesophagus ${ }^{6}$} & Reflux oesophagitis & $3(4.67 \%)$ \\
\hline & & & Barrett oesophagus & $1(1.57 \%)$ \\
\hline & & & Candidal oesophagitis & $1(1.57 \%)$ \\
\hline & & & Healed oesophageal ulcer & $r \quad 1(1.57 \%)$ \\
\hline & & \multirow{5}{*}{ Stomach $^{6}$} & Chronic atrophic gastritis & s $2(3.12 \%)$ \\
\hline & & & Eosinophilic gastritis & $1(1.57 \%)$ \\
\hline & & & $\begin{array}{l}\text { Granulation of chronic } \\
\text { inflammation-peptic } \\
\text { ulcer origin }\end{array}$ & $1(1.57 \%)$ \\
\hline & & & Acute on chronic gastritis & s $1(1.57 \%)$ \\
\hline & & & $\begin{array}{l}\text { Chronic non-specific } \\
\text { gastritis }\end{array}$ & $1(1.57 \%)$ \\
\hline & & \multirow{6}{*}{ Duodenum ${ }^{21}$} & $\begin{array}{c}\text { Eosinophilic enteritis / } \\
\text { duodenitis }\end{array}$ & $9(14.06 \%)$ \\
\hline & & & $\begin{array}{l}\text { Chronic non-specific } \\
\text { inflammation }\end{array}$ & $4(6.25 \%)$ \\
\hline & & & Celiac disease & $2(3.12 \%)$ \\
\hline & & & Tropical sprue & $2(3.12 \%)$ \\
\hline & & & Non-specific duodenitis & $3(4.67 \%)$ \\
\hline & & & Granulation of ulcer & $1(1.57 \%)$ \\
\hline & $\begin{array}{l}\text { Non-specific } \\
\text { lesions of } \\
\text { upper GIT } \\
(\mathrm{N}=1)\end{array}$ & Oesophagus $^{1}$ & $\begin{array}{c}\text { Pseudoepitheliomatous } \\
\text { hyperplasia }\end{array}$ & $1(1.57 \%)$ \\
\hline \multirow{2}{*}{\multicolumn{2}{|c|}{ NAD 3 out of $64(4.69 \%)$}} & Oesophagus $^{2}$ & Normal morphology & $2(3.12 \%)$ \\
\hline & & Stomach ${ }^{1}$ & Normal morphology & $1(1.57 \%)$ \\
\hline
\end{tabular}

\begin{tabular}{|c|c|c|c|c|}
\hline & & $\begin{array}{c}\text { Site Wise } \\
\text { Distribution }\end{array}$ & $\begin{array}{l}\text { Histopathological } \\
\text { Diagnosis }\end{array}$ & Percentage \\
\hline \multirow{9}{*}{$\begin{array}{c}\text { Neo- } \\
\text { plastic } \\
\text { lesions of } \\
\text { upper } \\
\text { GIT } 27 \\
\text { out of } \\
64(42.18 \\
\%)\end{array}$} & $\begin{array}{l}\text { Benign lesions of } \\
\text { upper GIT }(\mathrm{N}=2)\end{array}$ & Stomach ${ }^{2}$ & $\begin{array}{l}\text { Benign epithelial polyp } \\
\text { of stomach }\end{array}$ & $2(3.12 \%)$ \\
\hline & \multirow{8}{*}{$\begin{array}{l}\text { Malignant lesions } \\
\text { of upper GIT } \\
\text { (N = 25) }\end{array}$} & \multirow{4}{*}{ Oesophagus ${ }^{15}$} & $\begin{array}{l}\text { Well differentiated } \\
\text { squamous cell } \\
\text { carcinoma (WD SCC) }\end{array}$ & $5(7.81 \%)$ \\
\hline & & & $\begin{array}{c}\text { Moderately } \\
\text { differentiated (MD SCC) }\end{array}$ & $4(6.25 \%)$ \\
\hline & & & $\begin{array}{l}\text { Poorly differentiated } \\
\text { SCC (PD SCC) }\end{array}$ & $4(6.25 \%)$ \\
\hline & & & WD adenocarcinoma & $2(3.12 \%)$ \\
\hline & & \multirow{3}{*}{ Stomach $^{10}$} & WD adenocarcinoma & $5(7.81 \%)$ \\
\hline & & & MD adenocarcinoma & $2(3.12 \%)$ \\
\hline & & & $\begin{array}{l}\text { Adenocarcinoma - } \\
\text { Signet cell type }\end{array}$ & $3(4.68 \%)$ \\
\hline & & Duodenum & - & - \\
\hline
\end{tabular}




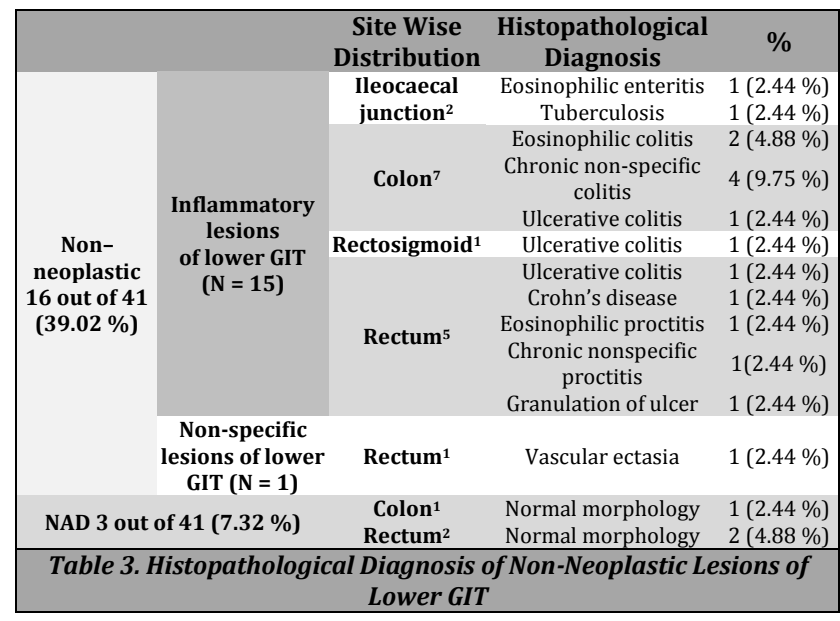

\begin{tabular}{|c|c|c|c|c|}
\hline & & $\begin{array}{c}\text { Site Wise } \\
\text { Distribution }\end{array}$ & $\begin{array}{l}\text { Histopathological } \\
\text { Diagnosis }\end{array}$ & $\%$ \\
\hline \multirow{11}{*}{$\begin{array}{c}\text { Neo-plastic } \\
\text { lesions of lower } \\
\text { GIT } 22 \text { out of } \\
41(53.66 \%)\end{array}$} & \multirow{3}{*}{$\begin{array}{l}\text { Benign lesions } \\
\text { of lower GIT } \\
(N=3)\end{array}$} & \multirow[t]{2}{*}{ Colon $^{2}$} & $\begin{array}{l}\text { Epithelial polyp of } \\
\text { sigmoid colon }\end{array}$ & $1(2.44 \%)$ \\
\hline & & & Adenomatous polyp & $1(2.44 \%)$ \\
\hline & & Anal canal ${ }^{1}$ & $\begin{array}{c}\text { Squamous papilloma } \\
\text { of anus }\end{array}$ & $1(2.44 \%)$ \\
\hline & \multirow{8}{*}{$\begin{array}{l}\text { Malignant } \\
\text { lesions } \\
\text { of lower GIT } \\
(\mathrm{N}=19)\end{array}$} & \multirow[b]{2}{*}{ Colon $^{7}$} & WD adenocarcinoma & $6(14.63 \%)$ \\
\hline & & & $\begin{array}{c}\text { Papillary } \\
\text { adenocarcinoma }\end{array}$ & $1(2.44 \%)$ \\
\hline & & \multirow{4}{*}{ Rectum $^{10}$} & WD adenocarcinoma & $4(9.75 \%)$ \\
\hline & & & MD adenocarcinoma & $2(4.88 \%)$ \\
\hline & & & $\begin{array}{c}\text { Papillary } \\
\text { adenocarcinoma }\end{array}$ & $2(4.88 \%)$ \\
\hline & & & $\begin{array}{c}\text { Signet ring } \\
\text { adenocarcinoma of } \\
\text { rectum }\end{array}$ & $2(4.88 \%)$ \\
\hline & & \multirow{2}{*}{ Anal canal ${ }^{2}$} & WD adenocarcinoma & $1(2.44 \%)$ \\
\hline & & & MD adenocarcinoma & $1(2.44 \%)$ \\
\hline
\end{tabular}

\section{DISCUSSION}

The variety of GI lesions encountered by using endoscopic biopsies were divided as oesophageal, gastric, duodenal and colonoscopic lesions. Among all the GI lesions of 105 biopsies there were 64 biopsies of upper GIT comprising of 25 oesophageal, 18 gastric, 21 duodenal biopsies and 41 (39\%) lower GI colonoscopic biopsies. In the present study the most common age group which was affected was 51 - 60 years in the upper GI and in the overall study also. This was in concordance with the study done by Javali et al. ${ }^{4}$ and Anoja Aparajita et al. ${ }^{5}$ they also had 51 - 60 years as the mean age which was affected. While, among lower GI biopsy cases the clustering was seen in 41 - 50 years of age group. This was also in concordance to B Vani et al. ${ }^{6}$ where the most commonly affected group was also 41 - 50 years.

\section{Oesophageal Lesions}

In our study there were 24 oesophageal biopsies out of which 7 were non neoplastic and 15 were neoplastic and 2 had normal morphology, it shows that the neoplastic conditions are predominant. Higher incidence of oesophageal carcinoma in this geographical region may be due to interplay of different environmental conditions such as dietary factors with underlying poor nutritional status. Consumption of red chillies which has substantial amounts of $\mathrm{N}$-nitroso compounds could also be a major contributing factor in this area. ${ }^{7}$ This finding is similar to the ones reported by Deepa Rani et al. ${ }^{8}$ and Nandini GV et al. ${ }^{1}$ The most common non-neoplastic lesion which was found among oesophageal biopsies was reflux oesophagitis. While, under neoplastic category squamous cell carcinoma of oesophagus was the most common accounting for 13 cases, 5 cases were well differentiated and 4 cases each of moderately and poorly differentiated. In the study done by Kontham Praveen et al. ${ }^{9}$ in 2016, the commonest oesophageal lesion was esophagitis under non-neoplastic category and squamous cell carcinoma in malignant. Similar studies like Krishnappa et al. ${ }^{10}$ Javali et al. ${ }^{4}$ Somani et al. ${ }^{11}$ also found oesophagitis as the most common.

\section{Gastric Lesions}

There were 19 gastric biopsies out of which 6 were non neoplastic, 12 were neoplastic and remaining 1 had normal morphology. In our study the most common non-neoplastic lesion which was found among gastric biopsies was chronic atrophic gastritis, accounting for 2 cases among 6 non neoplastic lesions. While, under neoplastic category adenocarcinoma of stomach was the most common, accounting for 10 cases out of 12 . Similar to our findings of non-neoplastic lesions, other studies which have found these results are Krishnappa et al.10 Thapa et al. ${ }^{12}$ Javali et al. ${ }^{4}$ Somani et al. ${ }^{11}$ and Bhatt $\mathrm{N}$ et al. ${ }^{7}$ Adenocarcinoma of stomach was also the most common malignant lesion found in Krishnappa et al. ${ }^{10}$ Thapa et al. ${ }^{12}$ Somani et al. ${ }^{11}$ and Nazrin et al. ${ }^{13}$ Adenocarcinoma was the commonest tumour of the stomach.

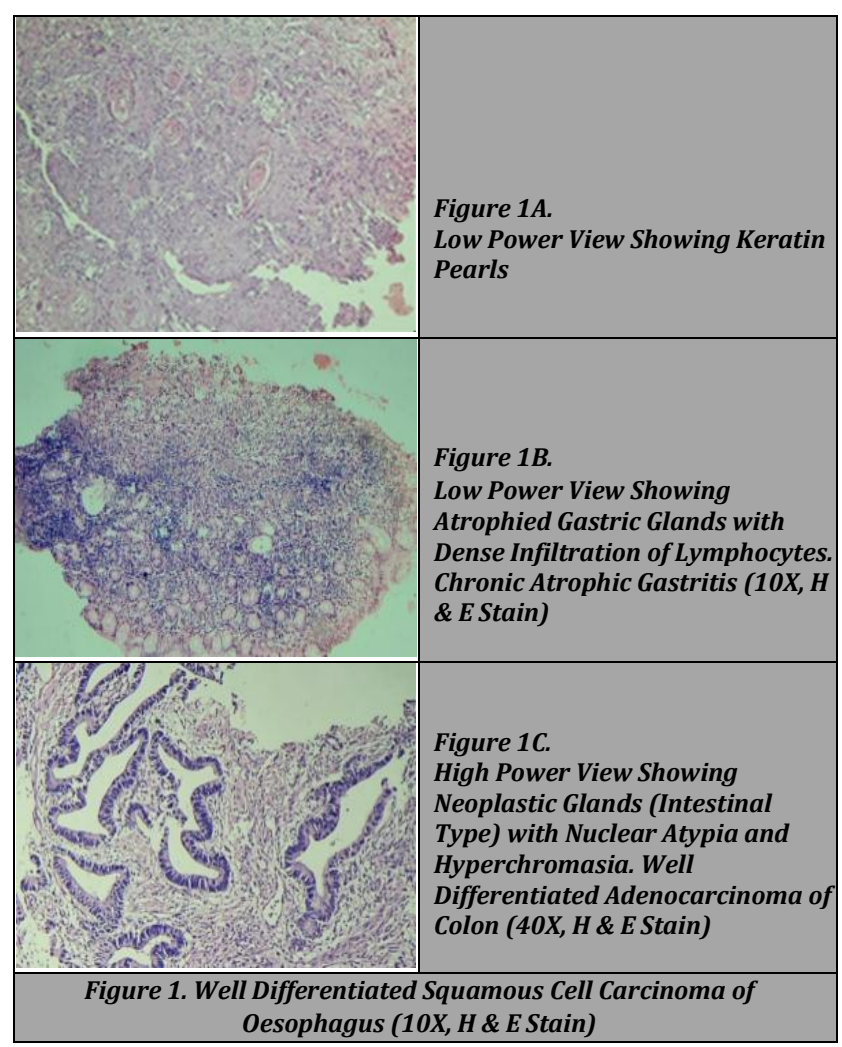

\section{Duodenal Lesions}

The most common non-neoplastic lesion which was found among duodenal biopsies was eosinophilic duodenitis. 
However, there were no cases of malignancy. No carcinoma was found in the study done by Anoja Aparajita et al. ${ }^{5}$ Study by Shanmugasamy K et al. ${ }^{14}$ also found inflammatory lesions to be more predominant compared to malignancy. Duodenum has a rapidly regenerative epithelial lining which can be easily affected by trauma, toxins and similar insults. ${ }^{15}$

\section{Colonoscopic Lesions}

Of total 105 cases there were 41 lower GI biopsies out which 16 were non neoplastic and 22 were neoplastic and 3 had normal morphology among non-neoplastic cases, the most common finding was of chronic non-specific colitis. Study done by Megha Shukla Pandey et al. ${ }^{16}$ Shefali et al. ${ }^{17}$ Rajbhandari et al. ${ }^{18}$ Akansha jain et al. ${ }^{19}$ also found chronic non-specific colitis. Heymann et al. suggested that the presence of chronic nonspecific inflammation of colon may represent the early stages of inflammatory bowel diseases like ulcerative colitis or Crohn's disease.20 Colorectal adenocarcinoma was the predominant malignant lesion which was found under neoplastic category. Studies which has shown similar results were Isoken $\mathrm{O}$ M Umana et al. ${ }^{21}$ and Akansha Jain et al. ${ }^{19}$

\section{CONCLUSIONS}

Performing endoscopy alone remains an incomplete investigative modality for the diagnosis of both upper GI and lower GI lesions; however, when used in combination with biopsy study, it becomes more diagnostically accurate and thus becomes advantageous for the better treatment and for predicting the prognosis of the patient.

Data sharing statement provided by the authors is available with the full text of this article at jemds.com.

Financial or other competing interests: None.

Disclosure forms provided by the authors are available with the full text of this article at jemds.com.

\section{REFERENCES}

[1] Nandini GV, Rakshitha HB, Doddikoppad MM, et al. Histopathological study of endoscopic biopsies of Oesophagus. Int J Clin Diagn Pathol 2018;1(2):07-13.

[2] Islam SMJ, Ahmed ASMM, Ahmad MSU, et al. Endoscopic and histologic diagnosis of upper gastrointestinal lesions, experience in a port city of Bangladesh. Chattagram MaaO-Shishu Hospital Med Coll J 2014;13(3):11-4.

[3] Teriaky A, Al-Nasser A, McLean C, et al. The utility of endoscopic biopsies in patients with normal upper endoscopy. Can J Gastroenterol Hepatol 2016;2016:3026563.

[4] Javali S, Madan M, Harendrakumar M, et al. Role of endoscopy in evaluating upper gastrointestinal tract lesions in rural population. J Dig Endosc 2015;6(2):59.

[5] Aparajita A, Mohanty RC, Sahu AA, et al. Histomorphological study of upper GI endoscopic biopsies. Int J Health Sci 2016;6(12):59-64.
[6] Vani B, Cheruku S. Spectrum of histopathological study of colonoscopic biopsies in a tertiary care hospital JMSCR 2019;7(11):517-23.

[7] Bhat N, Sheikh BA, Mir JN, et al. Histopathological study of upper gastrointestinal endoscopic biopsies-1 year prospective study. Br Biomed Bull 2018;6(2):315.

[8] Rani D, Bhuvan S, Gupta A. A study of morphological spectrum of upper gastrointestinal tract lesions by endoscopy and correlation between endoscopic and histopathological findings. Indian J Pathol Oncol 2019;6(1):28-34.

[9] Praveen K, Begum F, Kumar KM. Study of histopathological types of gastro-intestinal lesions by endoscopic biopsy. International Archives of Integrated Medicine 2016;3(11):46-53.

[10] Rashmi K, Horakerappa MS, Karar A, et al. A study on histopathological spectrum of upper gastrointestinal tract endoscopic biopsies. Int J Med Res Health Sci 2013;2(3):418-24.

[11] Somani NS, Patil P. Histopathological study of the upper gastrointestinal tract endoscopic biopsies. Ann Pathol Lab Med 2018;5(8):A683-8.

[12] Thapa R, Lakhey M, Yadav PK, et al. Histopathological study of endoscopic biopsies. JNMA J Nepal Med Assoc 2013;52(6):354-6.

[13] Nazrin MS, Ferdous NEJ, Saha M, et al. Histopathological study of upper gastrointestinal tract endoscopic biopsies. J Curr Adv Med Res 2019;6(1):42-6.

[14] Shanmugasamy K, Bhavani K, Narashiman R, et al. Clinical correlation of upper gastrointestinal endoscopic biopsies with histopathological findings and to study the histopathological profile of various neoplastic and nonneoplastic lesions. J Pharm Biomed Sci 2016;6(3):220-4.

[15] Memon F, Baloch K, Memon AF. Upper gastrointestinal endoscopic biopsy: morphological spectrum of lesions. Prof Med J 2015;22(12):1574-9.

[16] Pandey MS, Pandey A, Dombale VD. Histomorphological profile of colonoscopic biopsies-a two year study in a tertiary care hospital in South India. International Journal of Science and Research 2013;5(2):1513-8.

[17] Karve SH, Vidya K, Shivarudrappa AS, et al. The spectrum of colonic lesions; a clinico-pathological study of colonic biopsies. Indian J Pathol Oncol 2015;2(4):189-209.

[18] Rajbhandari M, Karmacharya A, Khanal K, et al. Histomorphological profile of colonoscopic biopsies and pattern of colorectal carcinoma in Kavre District. Kathmandu Univ Med J (KUMJ) 2015;11(43):196-200.

[19] Tignath G, Jain A. Histopathological spectrum of colonoscopic biopsies: a three years study from Central India. Int J Med Sci Innov Res (IJMSIR) 2018;3(4):56-9.

[20] Heyman MB, Perman JA, Ferrell LD, et al. Chronic nonspecific inflammatory bowel disease of the cecum and proximal colon in children with grossly normal-appearing colonic mucosa: diagnosis by colonoscopic biopsies. Pediatrics 1987;80(2):255-61.

[21] Umana IOM, Obaseki DE, Ekanem VJ. The clinicopathological features of lower gastrointestinal tract endoscopic biopsies in Benin City, Nigeria. Saudi Surg J 2017;5(1):9-20. 